\title{
From paper to program: Successfully translating an idea into a reality
}

Marion Minis

marion.minis@crisscross.cc

\begin{abstract}
No matter how excellent a framework for a new program is or how great it looks on paper, the challenge is how to 'translate' it into practice in such a way that it is an asset to the paid staff, volunteers and children involved. In this article, experiences of program development and delivery at Criss Cross Consultancy (CCC), where programs to empower vulnerable people are designed, are shared. With reference to the Good Practice Framework, the article draws on extensive program management experience to explore how good communication can support the effective design, implementation and delivery of programs. It illustrates the link between practice, meaningful communication and inclusion. Meaningful communication enables program content to be designed and adjusted to meet the needs of staff and children; shared decision-making to build co-ownership; recognition of expertise and matching people to roles; and effective top-down and bottom-up communication practices that engage with everyone. These communication outcomes are explored and examples are provided to illustrate how meaningful communication underpins the success of translating a program idea into a reality.
\end{abstract}

\section{Introduction}

Translating a great idea for a program into a reality and providing positive outcomes for everyone involved is challenging. At Criss Cross Consultancy (CCC), we design programs to empower vulnerable people. I draw on my program management experience to reflect on the potential of the Good Practice Principles for Youth Development Organisations (Seymour 2012) for guiding meaningful communication and supporting the translation of new ideas into program practice. The experience of CCC is that flexible and shared decision-making relies on both top-down and bottom-up communication, enabling program co-ownership and contributing to positive outcomes for staff, volunteers, children and communities. In light of this experience, a major strength of the YDRP framework is its openness to this two-way communication.

\section{About Criss Cross Consultancy (CCC)}

CCC is located in Rotterdam in the Netherlands. Our programs have as their over-arching purpose the empowerment and strengthening of children between the 
ages of four and fifteen years who live in economically deprived areas by offering them a series of interlinked and interactive activities in their communities. CCC's programs offer innovative ways of working to address the needs of the children themselves, as expressed to the practitioners who work with them. The aim of CCC practitioners is to make children's voices heard. The programs are financed by a mix of fundraising, subsidies and donations, and they run on average for between six and fifteen months. While CCC manages these programs, we share some of the key steps for successfully delivering them with a diversity of organisations and people from community centres, schools, cultural and sports organisations to youth workers, sporting coaches, artists, volunteers and children themselves. The YDRP Good Practice Framework mirrors and consolidates the direct experience of CCC and offers us firm guidelines for developing and evaluating quality programs and developing the potential of youth program work to better advantage children.

At CCC, we have seen how children's positive development and empowerment are supported when a diversity of organisations and people combine forces and collaborate to deliver programs. Our programs offer children opportunities to learn important life-skills as they take part in experiential programs consisting of activities located in community centres close to their homes. Children are supported to apply new skills, knowledge and techniques, and to use new kinds of materials and equipment, and they are encouraged to learn by discussing ideas, listening to each other, reflecting on what they do and learning from and inspiring each other. CCC especially encourages play as a means by which children gain renewed confidence and discover new qualities and skills. The benefits of involving a diversity of organisations and people also flow to youth work practitioners, who gain the opportunity to develop new ideas and approaches to working with children.

\section{Linking practice and meaningful communication}

When designing and implementing a new program, we always build flexibility into our program development plan and delivery model. Flexibility enables youth workers and children to say what they think and to influence the structure and content of the program and its activities. Our experience has shown us that to work successfully with different organisations, paid staff, volunteers and children, we need to be open to change and to practise shared decision-making at different levels and stages of the program-development and delivery process. Practising flexibility and shared decision-making actively supports meaningful communication and inclusive outcomes.

Our programs are implemented in different urban areas and cities. While children living in these areas may share many characteristics, needs and interests, they are all individuals. This means we need to be open to seeking each young person's views and opinions, listening to them, and adjusting program content to their developmental needs and aspirations as well as to the culture of their neighbourhood. The diversity of program locations also means the program manager is often not located in the community where the program of activities will be provided. This means that when we are planning our programs, it is of utmost importance that we adopt best practice in communication with everyone. 
The paid staff and volunteers who deliver our programs are also diverse. They have different needs and interests, and bring the insights of distinct expertise. Good communication requires us to discuss with our staff their and our expectations. For professional, paid staff, we need to make sure that participating in the program will work for them, giving them professional opportunities and advantages. Youth workers bring extensive knowledge and expertise to our programs. They know their clients and community well, can judge what will and will not work, and know how to listen to children - so we need to listen to them! When planning a program, we therefore guide every practitioner step by step through all elements of the program and explore these elements with them, discuss their professional needs, targets and challenges, and map together how the program will work. It is through this discussion that we first work together to build program co-ownership and discover how to incorporate themes of specific concern to their community into the program without undermining the framework of the program.

Volunteers are also indispensable for the successful execution of many of our programs. Volunteering women and men come from various backgrounds and have different skills, motivations and learning needs. As a rule, candidates for volunteer positions are asked why they want to be involved and what they would like to gain from being involved. We have worked with all kinds of volunteers, from those for whom volunteering is a way to express their social commitment to those who have very specific skills, needs and interests that they want to share and explore. Usually, with some creativity, most people who want to volunteer are given a role or position matched to their qualities and preferences. We rarely have to turn down applicants (van der Heijden 2010, 2013).

Building in diverse opportunities for volunteers to be a part of the program, showing their efforts are appreciated and ensuring both volunteers and professionals understand each other's roles - who is doing what and who is responsible for what and to whom - are essential for successful volunteer and paid staff engagement, program delivery and outcomes for children. We also provide targeted training and coaching for volunteers to ensure that they are suited to working with children. Successful staff engagement not only strengthens the capacity of our programs but also leads to dedicated and committed professional and volunteer staff who, depending on their role, can also act as positive role models to children.

Once our programs are being delivered, we actively work to share program decision-making and continue to work on building program co-ownership. Good practices in top-down and bottom-up communication, supported by an open way of working, invite continuous feedback. Effective and meaningful continuous feedback processes involve being open to listening to any kind of feedback, providing multiple opportunities for paid staff and volunteers to participate in decision-making and supporting children to do so too. In our experience, this style of respectful meeting of top-down and bottom-up communication creates opportunities for everyone to participate in decisions, which builds program co-ownership. Bottomup communication is the only way we can understand how a program needs to evolve by listening to feedback about what is working and what needs fine tuning (Minis and van Dijcke 2015; Minis and Verhoeven 2006; Verhoeven and Minis 2001). 


\section{Case studies: Adjusting content, being flexible}

\section{Moving activities outdoors}

One of our programs is called 'Dream Team Time' (2007). It aims to raise awareness of ancient civilisations and their cultural expressions, by practising arts and crafts techniques inspired by these civilisations in workshops led by professional artists. The program was delivered in seventeen community centres and at several primary schools in Rotterdam, Utrecht and Haarlem. In total, 268 children participated, of which thirty-eight children belonged to the youngest age group, from four to seven years; the majority of 181 children were between the ages of seven and twelve years; and forty-nine participants were aged from twelve to fifteen years. The ratio of girls to boys was 58 to 42 per cent.

Following consultations with children about the kinds of activities they wanted, a youth worker suggested having some of the program activity classes outdoors. This idea was welcomed by the participating artist and resulted in groups of children jointly painting a selection of their sketches on a large scale, on the pavement of a playground. The artist climbed a ladder to take photos of the children and their joint artworks. These pictures were shown at an exhibition in the ABC Museum in Haarlem, in the presence of proud children and parents (Koenen and van der Heijden 2008). This was an effective program demonstrating flexible communication.

\section{Engaging family}

Another of our programs, called 'PassieKids', conducted from March 2011 to June 2012, aimed to reach out to twenty-three groups of youth in community homes, several day care centres and a few schools in five Dutch cities: Utrecht, Amersfoort, Rotterdam, Haarlem and Tilburg. It comprised a series of interactive classes on arts and crafts techniques focused on visualisation of personal passions. The creative results were shown at a public exhibition in each city. The ratio of girls to boys was 56 to 44 per cent. The youngest age group (four to seven years) had 112 participants, while the eight to twelve years age group had 224 children, and the thirteen to fifteen years group comprised thirty-five children (in total, there were 371 participants).

As the program unfolded, some children indicated that they wanted their parents to join in the activities. Parents and carers were therefore invited by the children, with support from staff, to participate in some workshops. It was a delight to see how eagerly the parents and carers accepted this invitation. Moreover, it was a privilege for us in CCC to witness the generations working together on stilllife studies of summer fruits and flowers, a new experience for all of them. The creative results comprised both individual paintings and drawings, and several group artworks. This program was a successful example of joint learning in openended, creative inter-generational activities (Verhoeven and Minis 2003; van der Heijden 2013).

\section{Responding to gender}

CCC aims to instil a love of sport and art together in another of our programs, called 'KunstScoren', conducted from September 2005 to July 2006. This program consisted of a series of interactive workshops for children facilitated by professionals on dance (break dance, street dance and bobbling), rap singing, stage 


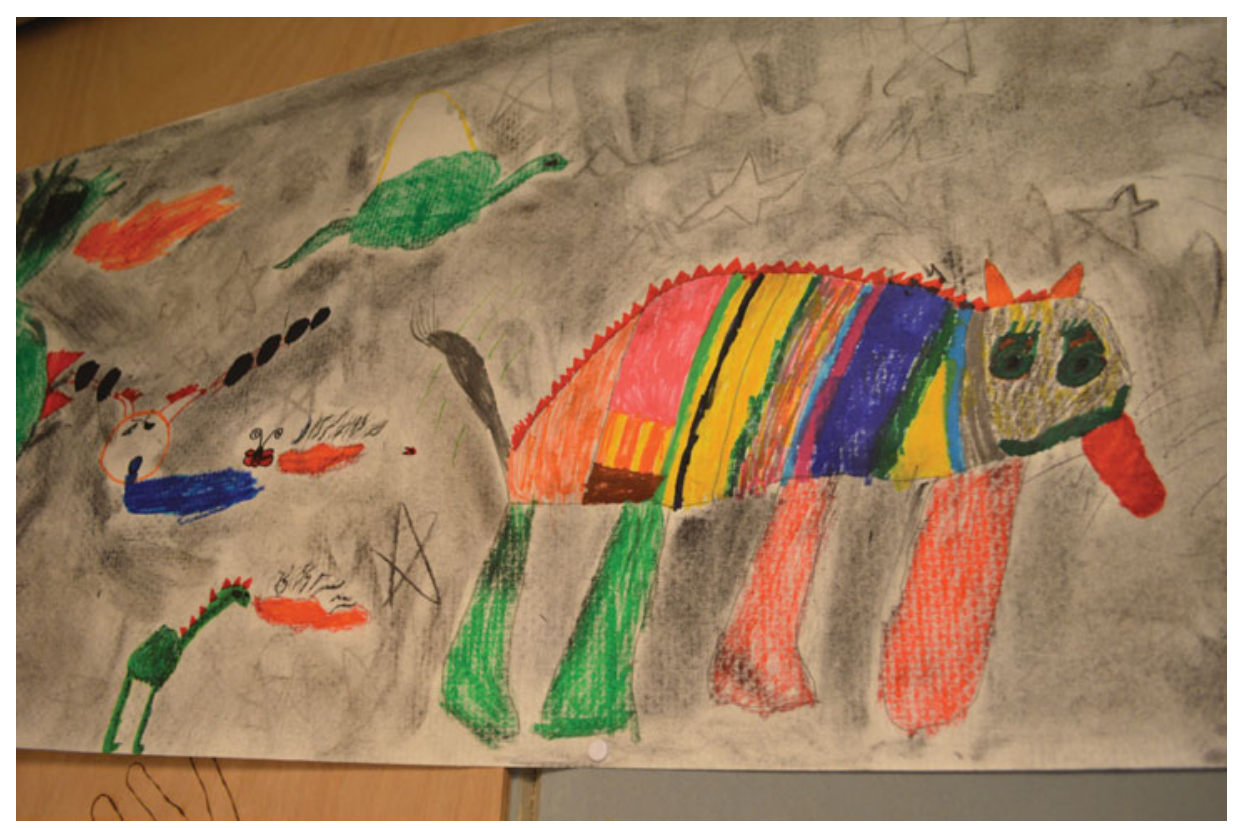

Figure 1

(Colour online) Impression of the exhibition MooiMaken! in community centre Amersfoort Ondemeemt, Amersfoort. Reproduced with permission of Jeroen Vos.

improvisation and visual arts. 'KunstScoren' was delivered in nineteen community centres in Rotterdam, in the city councils of IJsselmonde, Feijenoord, Prins Alexander and Delfshaven. Workshops involved presentations of dance, sports and music by and for children, their parents and carers at four Local Cultural Centres (LCCs), followed by exhibitions at the Centrale Bibliotheek Rotterdam (Main City Library) and Villa Zebra art centre for children. 'KunstScoren' engaged a total of 288 participants, of whom fifty-seven belonged to the youngest age group of four to seven years, 144 were between and twelve years, and eight-seven were aged from twelve to fifteen years. The ratio of girls to boys was 58 per cent to 42 per cent. On the basis of meeting with our project partners, CCC determined that community centres were mainly offering activities that appealed to boys. When we discussed this with both youth workers and girls, the girls reported that they preferred other types of activities and did not always feel welcome in the centre. Their requests were woven into our program in a cycle of continuous feedback and improvement. The results were that many more girls participated.

In another of our programs, called 'MooiMaken!', conducted from March 2014 to March 2015), we aimed to empower children through series of interactive classes on practising creative self-expression guided by professional artists. The program was delivered in twenty-three community centres in Haarlem, Rotterdam, Utrecht and Amersfoort, and the wrap-ups of these classes comprised presentations in community centres to involve inhabitants of the community. These community presentations were followed by a group exhibition in a museum in each city, along with open stages, dance performances, singing and music by children - all in 
celebration of the opening of each exhibition. 'MooiMaken!' included eighty-seven children aged from four to seven years and 267 participants aged from eight to thirteen years. The ratio of girls to boys was 51 to 49 per cent. This was an example of a successful program that involved working with groups of children from small communities of conservative Muslim families from economically deprived areas of rural Turkey and Morocco. We found that we could not attract both girls and boys to participate in our program activities because mixed groups generally were not accepted in these communities. To encourage and enable both girls and boys to benefit from participating in our programs, we successfully introduced single-sex group activities.

Together, these case studies show that working together on all levels of a program while maintaining a flexible and open communications structure leads to real and meaningful results that work for the children and their communities, practitioners and members of staff. While the way we design our activities can result in inclusion, design can also result in exclusion. It is crucial, therefore, to keep an open mind and take the aims, needs of the children and practitioners as leading elements in program design.

\section{Conclusion}

At CCC, we have found that our work in successfully turning new program ideas into a reality is strengthened by working collaboratively with a diversity of people from different types of organisations, in different cities and with different interests, needs and skills. In this article, I have shown how in our work the good practice theme of effective and open communication is used to enhance the quality of our programs, to the advantage of youth workers, children and the community. Good communication is at the heart of any successful program: it is the element that glues all program elements together and is especially important when a program is designed to be flexible and to evolve organically within an established framework.

Devoting attention to all aspects of communication, from making sure everyone understands their role and keeping everyone informed, to providing feedback and coaching, and listening to practitioner and youth experiences and suggestions, is essential. To deliver successful programs that meet the learning needs and interests of children, and that respect their expertise as well as the expertise of our staff, we have learnt to accept change, to build flexibility into a program at all levels and to support youth workers to alter the program of activities to suit their community.

We support youth workers and children to participate in defining our programs and, once the implementation has begun, to also influence how the program evolves. Valuing this first-hand information enables us to work together to adjust the program so that it better meets practitioner and participant needs and interests while maintaining the program's purpose. There is no doubt that when translating an idea for a program into a reality, the type of communication adopted from the outset will make or break the idea. Meaningful and empowered bottom-up communication is, in my view, the glue that keeps it all together.

\section{Acknowledgements}

For financial support: MooiMaken! (2014-15) — program partners combined with funding from VSB, Boschuysen, Prins Bernard Cultuurfonds, kfHein fonds, 
Elise Mathilde Fonds, Madurodam Steunfonds and anonymous donors; Passiekids (2011-12) - program partners combined with funding from the local governments of Rotterdam and Amersfoort, Korinthiërsfonds, VSB, J.C. Ruigrok, Animus Donandi, kfHein fonds and anonymous donors; Dream Team Time (2007) — program partners combined with support of the city council of Delfshaven and funding from Lindenweij Fonds, VSB, KfHEINfonds, Boschuysen, Madurodam Steunfonds, Carel Nengerman, Erasmusstichting and anonymous donors; KunstScoren (200405) - program partners and local government Rotterdam (Sportjaar 2005), city councils of Hoogvliet, Prins Alexander, Feijenoord and IJsselmonde and funding from VSB Rotterdam, SKVR, Prins Bernard Cultuurfonds, Nieuwe Rotterdamse Cultuur and anonymous donors.

\section{References}

Koenen H. and van der Heijden A. 2008. 'Dream team time 2007', programma evaluatie, Stichting Culturall and Criss Cross Consultancy, Rotterdam.

Minis M. and van Dijcke K. 2015. 'MooiMaken! (2014-15)', programma evaluatie. Rotterdam: Stichting Culturall and Criss Cross Consultancy.

Minis M. and Verhoeven B. 2006. Evaluatie rapportage 'KunstScoren (2005-06)', Stichting Culturall and Criss Cross Consultancy, Rotterdam.

Seymour K. 2012. Good practice principles for youth development organisations. 2nd ed. Brisbane: Key Centre for Ethics, Law, Justice and Governance, Griffith University.

van der Heijden A. 2010. 'ASOkunst! De Dialoog (2009-2010)', programma evaluatie. Rotterdam: Stichting Culturall and Criss Cross Consultancy.

-2013. Evaluatie 'Passiekids (2011-2012)'. Rotterdam: Stichting Culturall and Criss Cross Consultancy.

Verhoeven B. and Minis M. 2003. Evaluatie 'Offline (2002-03)', Stichting Culturall and Criss Cross Consultancy, Rotterdam.

Verhoeven B., Minis M. (2001), 'KidsKunst Miniatuurkunst(2000-01)', programma evaluatie. Rotterdam: Stichting Culturall and Criss Cross Consultancy. 